\title{
CONSTRUÇÃo do TElescóPIO de baixo CUSTO PARA O ESTUDO DE ASTRONOMIA
}

\author{
THE CONSTRUCTION OF A LOW COST TELESCOPE FOR THE STUDY OF \\ ASTRONOMY
}

DOI: http://dx.doi.org/10.23926/RPD.2526-2149.2019.v4.n1.p242-254.id428

\section{Giovane Barbosa \\ Aragão \\ Licenciando em Física \\ (IFMT -Campus Confresa) \\ giovanearagao@gmail.com}

\section{Livia Kamila Oliveira Milhomem}

Licencianda em Física

(IFMT -Campus Confresa)

liviakamila3@gmail.com

\section{Divino Eduardo}

Duarte Rodrigues

Licenciando em Física

(IFMT -Campus Confresa)

divinoeduardoduarterodrigue

s@gmail.com

\section{Tiana Vieira dos \\ Santos}

Licencianda em Física

(IFMT- Campus Confresa)

tianajt17@gmail.com
Resumo: O presente artigo descreve uma sequência didática na construção do telescópio caseiro, mostrando o passo a passo da montagem e aplicação em sala. É um trabalho que envolve licenciandos do curso de física do IFMT-Campus Confresa, e estudantes da Escola Estadual da Policia Militar Tiradentes do mesmo município. A partir dessa interação foram realizadas reuniões e grupos de estudo para a montagem do equipamento para observação de corpos celestes. Deu-se ênfase no custo do material usado na confecção da luneta e nos conceitos que poderiam ser abordados. O objetivo do estudo foi demonstrar que a busca do conhecimento na área de Física Experimental depende da vontade dos estudantes e do incentivo do docente. Além de ser um material de baixo custo, pode levar as pessoas ao conhecimento de forma simples.

Palavras-chave: Telescópio; Material Alternativo; Ensino; Astronomia.

\begin{abstract}
The present article, describes the didactic sequence in the construction of a home-made telescope, showing the steps of its assembling. It is a work in which students fron the Physics degree of IFMT-Campus Confresa, Gadthered witch the students fron confresa's Military School Tiradentes. Fron this interaction, meetings and study groups were carried out to the equipment's assembling and, further observation of celestial bodies. Emphasis was given on the cost of the material used to build the equipment. The main objective was to show that the searching for knowledge in the experimental physics area depends upon the students' wish as well as the teacher's stimulus. The articles is also to show how low cost material can lead people to knowledge in a simple way.

Keywords: Telescope; Alternative Material; Teaching; Astronomy.
\end{abstract}




\section{INTRODUÇÃO}

O interesse pela ciência surge por diversas razões, através de uma reportagem ou por uma experiência realizada na escola, ou mesmo no dia a dia. A Astronomia é uma das ciências mais antigas, estuda os corpos celestes (como estrelas, planetas, cometas, nebulosas e galáxias) e os fenômenos que se originam fora da atmosfera Terrestre. Essa Ciência consegue atrair olhares, não apenas por seu encanto natural, mas também pelo mistério que a cerca. Entretanto, além de fascinante é pouco conhecida pela maioria das pessoas, por não terem conhecimento específico ou por ser um tema considerado sem importância para alguns, é um estudo de pouquíssimo incentivo nas escolas, e assuntos que ainda intrigam a sociedade moderna (DAMASCENO, 2016)

O Estudo da Astronomia iniciou-se a partir da observação celeste e sequencialmente evoluindo para utilização de alguns instrumentos. Porém devido à sua amplitude, nota-se que há uma falta de incentivo para o estudo dessa ciência, consequentemente, pouco interesse de alguns acadêmicos sobre o conhecimento astronômico, pois não conseguem vislumbrar sua magnitude. Tornando-se assim, necessária a aplicação de métodos que facilitem a compreensão dos conteúdos (DAMASCENO, 2016). Sendo uma das opções o uso de materiais alternativos como o telescópio para isso.

Em 1609, Galileu Galilei ouviu falar de um novo instrumento que consistia num tubo com duas lentes e que permitia ver os objetos como se eles estivessem mais próximos. Com base nessa informação Galilei criou seu telescópio, mais conhecido como luneta (SOUZA, 2006). Com o telescópio refrator ou luneta é capaz de se observar fenômenos celestes como manchas solares, relevos e crateras lunares, fases de vênus, satélites de júpiter, entre outros que só são possíveis ser observados por grandes telescópios (SOUZA, 2006). A ideia de utilizar os telescópios como meio para observar o espaço foi um degrau de suma importância para o desenvolvimento da sociedade. Hoje existem dois grupos de telescópios: o Refrator/luneta de Galileu e o Refletor de Newton. Também possui os dióptricos que são refletores, porém mais caros. Esses instrumentos servem como métodos que auxiliam na aprendizagem em sala de aula (SOUZA, 2006).

Levando-se em consideração a importância e seu poder de observação, torna-se necessário a construção de um telescópio artesanal, para estudantes do ensino médio e fundamental, com a proposta de aumentar o interesse pela astronomia e conhecer os conceitos físicos abordados. Este trabalho tem o objetivo de apresentar uma sequência didática envolvendo a construção do telescópio caseiro ou luneta, com material alternativo, métodos 
artesanais e de baixo custo. Por esses motivos o objeto torna-se acessível a todos colaborando com aspectos teóricos e propostas de utilização em sala de aula.

\title{
2 REFERENCIAL TEÓRICO
}

O estudo astronômico foi capaz de trazer muitas descobertas ao mundo moderno, porém tudo surgiu há anos atrás. Dentre elas estão o primeiro relógio de sol datado de 3.500 a.C., o primeiro Mapa Astronômico pelo matemático grego Eudoxo de Cnidos 600 a.C., a descoberta da circunferência da terra por Eratóstenes 240 a.C., entre outras inúmeras descobertas, entretanto tudo o que se sabia era bastante restrito, pois dependia apenas do visivelmente nu para alguma descoberta astronômica. Então, com o passar dos anos surge o telescópio em 1609, inicialmente um material simples, mas capaz de se observar os astros. Sendo assim, Galilei descreve os primeiros fenômenos astronômicos ocultos à visão humana (SOUZA, 2006).

O telescópio de baixo custo é um material alternativo didático usado no ensino de Astronomia, sua principal função é observar fenômenos celestes aproximando-os, facilitando ao observador os movimentos estelares ou mudanças astronômicas (MARQUES; DORES; SILVA, 2015). Como o telescópio ajuda no ensino e aprendizagem de Astronomia é significativamente importante que a escola possua esse equipamento. Além da disciplina de Astronomia nos proporcionar uma vasta descrição de temas a ser estudados, também proporciona a criatividade no uso de materiais alternativos.

Segundo Langui (2012, p. 109):

\begin{abstract}
A Astronomia, pela diversidade dos problemas que propõe e dos meios que utiliza, oferece o ensejo de contato com atividades e desenvolvimento de habilidades úteis em todos os ramos do saber e do cotidiano da ciência. A Astronomia oferece ao educando, como nenhum outro ramo da ciência, a oportunidade de uma visão global do desenvolvimento do conhecimento humano em relação ao Universo que o cerca.
\end{abstract}

O primeiro tubo de observação que possuía lente foi desenvolvido em 1608 por Hans, dono de uma fábrica de lentes, porém foi usado para fins bélicos (SOUZA, 2006). Um ano a frente, em 1609, foi que Galileu Galilei usando a ideia de Hans decidiu construir um objeto para observação estelar. Esse objeto ficou mais conhecido como Luneta. Galilei descobriu muitos aspectos astronômicos, pois ter um objeto de aproximação facilitava seus estudos voltados aos movimentos dos astros e a partir disso pode contribuir para a teoria do Heliocentrismo (SOUZA, 2006).

Desde o telescópio de Galilei, o primeiro a ser usado para investigação astronômica, os objetos de observação foram estudados para aprimorar a imagem que possuíam. Alguns dos astrônomos como Niccolo Zucchi, Cavalieri, tentaram aprimorar postulando a ideia de um novo 
tipo de telescópio, o refletor, mas esse mérito foi dado a Issac Newton, pois ele foi o primeiro a construir esse tipo de telescópio (FRANCISCO, 2013). Desde então os telescópios são usados para observação, porém o custo econômico para adquirir um, construído por indústrias, é alto chegando a milhares de reais. Por esse motivo, a construção de um telescópio com recursos próprios pode sair bem mais barato do que um comprado em lojas externas.

Além da opção de uma aula didática para os estudantes, o desenvolvimento de um projeto dessa vertente será extremamente motivador. Para Langui (2012), "A Astronomia oferece oportunidade para atividades que envolvam também trabalho ao ar livre e que não exigem material ou laboratórios custosos". A vantagem de se obter esse material com uma alternativa econômica baixa está em dar a oportunidade para escolas que não o possuem de adquiri-lo.

Os materiais alternativos são uma didática instrumental, contudo deve ser trabalhada continuamente com uma relação teoria-prática (CANDAU, 2011). Essa relação trará significado a prática que os estudantes estarão desenvolvendo. Tais conteúdos são abordados nos períodos de ensino fundamental e médio, podendo ser de grande valia o uso do telescópio para melhor desenvolver a aula.

\section{Materiais e Métodos}

Atualmente, temos uma vasta opção de telescópios para o mercado em geral, entretanto os custos a aquisição são altos tornando-se mais difícil adquirir esse objeto para algumas instituições de ensino, em que a escola não possui recursos suficientes para esse tipo de investimento.

Pode-se apresentar o projeto da construção de um telescópio para a turma em dias específicos por exemplo, no dia da Astronomia (02 de Dezembro), ou mesmo em dias letivos comuns, o fato dos estudantes possuírem o material para o auxílio nos estudos de astronomia torna-se muito importante.

Uma das principais vantagens do telescópio desenvolvido com recursos próprios é que além do conhecimento adquirido ao construí-lo, o estudante desenvolve cálculos de óptica, em específico nas distâncias focais (Equação de Gauss) tornando a teoria bem mais atraente. Trabalha-se conceitos importantes como as Leis de Kepler, pois o objetivo não é apenas fazer um cálculo e sim aplicá-lo ao cotidiano do aluno.

Para a construção do Telescópio Refrator ou Luneta de Galileu, são necessários os materiais que seguem. 3 Canos de $1 \mathrm{~m}$ para tripé do telescópio; 1 cano $(50 \mathrm{~mm})$ de $40 \mathrm{~cm} ; 1$ 
cano $(40 \mathrm{~mm})$ de $20 \mathrm{~cm} ; 1$ cantoneira pequena; 1 adesivo epóxi em massa; 3 presilhas (enforca gato); Cola de cano; 10 Parafusos; 10 porcas e 10 Arruelas; Tinta Spray preta fosca; Lente de lupa de 0,40 m de foco; Objetiva de lanterna; Fita Dupla Face; Copo de macarrão instantâneo; Trena e Fita Isolante.

\subsection{SEQuênCIA Didática}

O custo com a confecção do telescópio alcançou o objetivo, com aproximadamente R $\$$ 70,00 foi totalizado o valor dos materiais, mão de obra simples e utilizadas poucas ferramentas. Foram realizados três encontros para a construção do Telescópio, com intuito de inteirar os estudantes da Escola Militar do $2^{\circ}$ ano do Ensino Médio e os Acadêmicos do curso de Física do IFMT- Campus Confresa e realizar uma abordagem inicial dos conteúdos. O primeiro encontro, para a apresentação do projeto mostrando o objetivo, as metas e os conceitos físicos a serem trabalhados. No segundo encontro, foi realizado o estudo da construção, orçamentos e compra dos materiais e entender o processo de montagem de acordo com o trabalho base que utilizamos para que este projeto fosse desenvolvido. O terceiro encontro foi para construção do Telescópio.

Para escolha da lente objetiva a ser utilizada para observação na luneta, foram analisados alguns trabalhos já existentes na construção do material alternativo, vídeos no Youtube, que indicavam opções de lentes para tal objeto, com a constatação de que: não poderia ser uma lente de grande alcance, pois teria que ser algo proporcional observando o foco da lente da lupa fixada.

$\mathrm{Na}$ etapa de construção, os estudantes e acadêmicos se reuniram e confeccionaram a luneta artesanal (telescópio). A turma participante foi o $2^{\circ}$ Ano do Ensino Médio, pois o assunto trabalhado na matriz curricular é a Óptica. Sendo assim, puderam aprofundar-se mais no assunto de refração, principalmente nos cálculos utilizados para o foco da lente do telescópio.

Inicialmente foi realizada uma sondagem para verificar os conceitos que os estudantes possuíam sobre Óptica Geométrica e as Leis de Kepler. No entanto, é interessante que o professor faça uma análise dos conhecimentos empíricos, associando a astronomia com o desenvolvimento tecnológico da humanidade.

Observando os conhecimentos prévios dos estudantes, pode-se realizar um debate e fazer algumas intervenções, explicando os principais conceitos de Óptica Geométrica, espelhos planos, côncavos e convexos, lentes convergentes, divergentes, esféricas e a Lei de Gauss, facilitando a associação dos conceitos teóricos ao que vai ser realizado na prática (FORNER, 2000). 
Para determinar a distância focal da lente esférica do telescópio foi necessário a aplicação da Equação de Gauss que é a seguinte:

$$
\frac{1}{f}=\frac{1}{p}+\frac{1}{p^{\prime}}
$$

Onde, $\boldsymbol{f}$ é a distância focal da lente, $\boldsymbol{p}$ é a distância do objeto à lente e $\boldsymbol{p}$ 'é a distância da imagem à lente esférica. Essa equação permite definir o foco da lente, como a distância do objeto. A lente colocada no telescópio serve para o aumento linear transversal.

O cálculo da imagem da lente utilizada foi desenvolvido da seguinte maneira: foi colocada uma moeda a $60 \mathrm{~cm}$ de distância da lente, a lente possui $20 \mathrm{~cm}$ de foco (trazida no rótulo do fabricante) e calculada a distância da imagem projetada a lente.

$$
\frac{1}{20}=\frac{1}{60}+\frac{1}{p^{\prime}} \rightarrow p^{\prime}=30 \mathrm{~cm}
$$

Com o resultado do cálculo, foi possível determinar o tamanho exato do cano onde iria fixar a lente, que foi de $30 \mathrm{~cm}$. Percebe-se que na prática a distância focal coincide com o resultado encontrado.

Após a construção da luneta e a observação lunar, foi possível observar que as Três Leis de Kepler é amplamente desenvolvidas no movimento astronômico, sendo que a $1^{\text {a }}$ lei das órbitas afirma que: os planetas possui órbitas elípticas em torno do sol; a $2^{\mathrm{a}}$ lei das áreas afirma que: o segmento que une um planeta ao sol descreve um espaço igual em intervalo de tempos iguais; a $3^{\mathrm{a}}$ lei dos períodos afirma que: $\mathrm{O}$ quociente dos quadrados dos períodos e o cubo de suas distâncias médias do sol é igual a uma constante $k$, igual a todos os planetas (SÓ FÍSICA, 2008-2019).

\section{Resultados e Discussão}

Na primeira semana de Dezembro de 2018 foi iniciada a construção do Telescópio caseiro, durante um período intercalado de 8 horas. O ambiente usado foi o laboratório de física do Instituto Federal de Educação, Ciência e Tecnologia de Mato Grosso - Campus Confresa (IFMT). No projeto abordado, o passo a passo da construção será descrito com as medidas que foram necessárias segundo a lente escolhida, lembrando que alterações de tamanho dos tubos podem mudar conforme a lente, porém a estrutura é a mesma para a luneta ou telescópio refrator.

Após a construção, a luneta foi levada para o observatório, onde foi possível focalizar as crateras lunares com uma resolução considerável, se tratando de um material alternativo construído de forma artesanal. As observações lunares foram feitas no campus e na escola 
Tiradentes com estudantes e componentes do grupo. As imagens visualizadas possuem algumas aberrações, são desvios de um sistema ótico das previsões da ótica paraxial (válida para ângulos pequenos em relação ao eixo de referência do sistema) capazes de produzir borramento na imagem, já que cada ponto do objeto não converge para um único ponto da imagem (FILHO, 2018).

Os materiais escolhidos para a construção seguem um padrão econômico acessível, visto que o objetivo é incentivar o estudo e despertar o interesse do estudante para área de Astronomia, principalmente para os padrões de escolas brasileiras, que em sua maioria não possuem aparatos laboratoriais para o ensino de ciências.

Segue sessão de fotos da montagem do telescópio:

Figura $1-1^{\circ}$ passo, $2^{\circ}$ passo e $3^{\circ}$ passo da montagem do telescópio

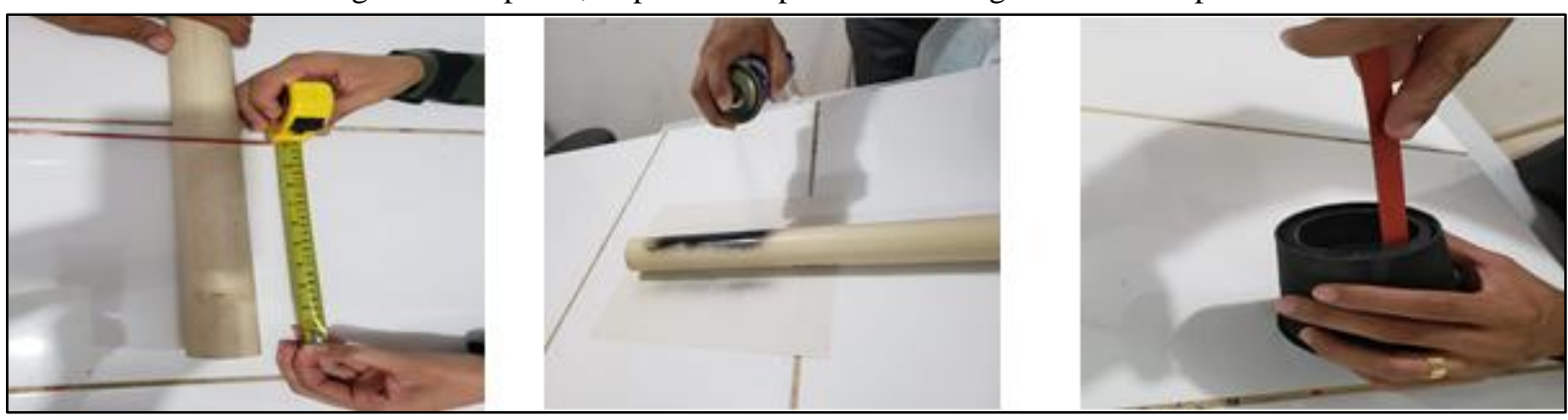

Fonte: arquivo pessoal

$1^{\mathrm{o}}$ passo - Corte os canos segundo as medidas da lente $(\mathrm{O}$ cano de $40 \mathrm{~mm}$ foi cortado de acordo com a medida do foco $(50 \mathrm{~cm})$ da lente, também o de $50 \mathrm{~mm}$ de $25 \mathrm{~cm}$ ).

$2^{\circ}$ passo - Pinte com tinta spray preta (facilita a observação, impedindo a penetração de raios de luz).

$3^{o}$ passo - Corte o fundo do copo plástico, conforme a medida do cano que será encaixado ( o cano de $25 \mathrm{~cm}$ será colocado no corte do copo).

Figura $2-4^{\circ}$ passo, $5^{\circ}$ passo e $6^{\circ}$ passo da montagem do telescópio

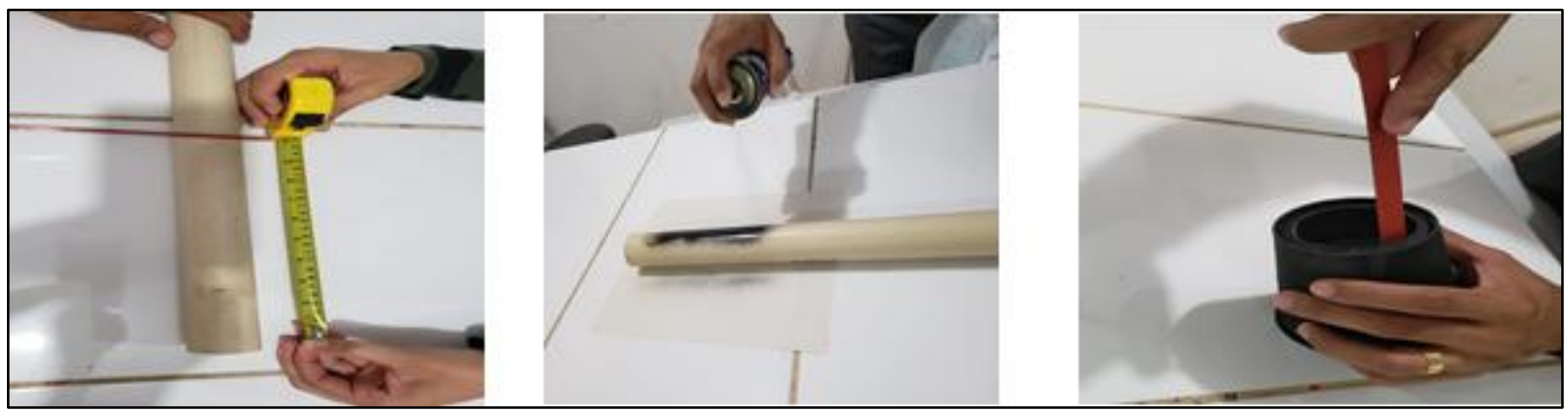

Fonte: arquivo pessoal 
$4^{\circ}$ passo - Encaixe a lente no copo plástico, dando suporte geral a ela e apoiando suas bordas uniformemente no copo, é preciso fixar com cola quente entre a borda e a lente. (copo de macarrão instantâneo)

$5^{\circ}$ passo - Monte a ocular do telescópio e use a lente de uma lanterna (Para construção deste em específico foi usada uma lente que aproxima até 20x)

$6^{\circ}$ passo - Fixe a lente a um cano de curto, aproximadamente $4 \mathrm{~cm}$, popular cano de joelho de meia polegada com adesivo epóxi.

Figura $3-7^{\circ}$ passo, $8^{\circ}$ passo e $9^{\circ}$ passo da montagem do telescópio

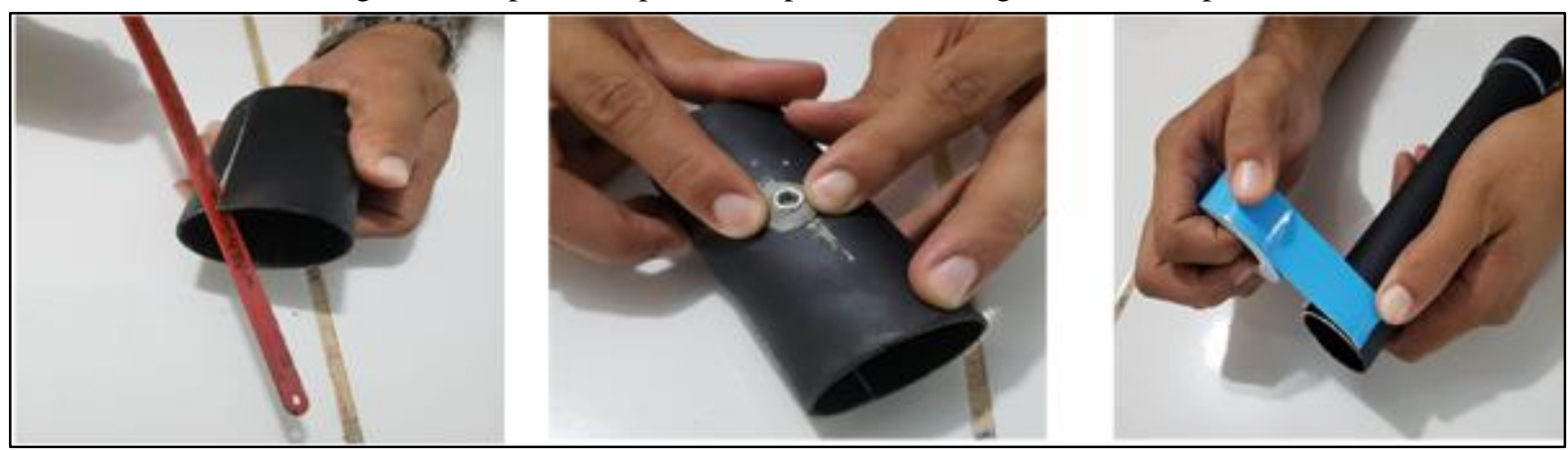

Fonte: arquivo pessoal

$7^{\circ}$ passo - Corte o cano de ligação entre a lupa e o tripé na vertical para realizar o encaixe (50 $\mathrm{mm}$ de diâmetro e $10 \mathrm{~cm}$ de comprimento).

(Obs. passo $6^{\circ}$ e $7^{\circ}$ - isso para tornar possível o ajuste do foco entre os dois tubos, que tem por objetivo aproximar ou distanciar o foco do que está sendo observado).

$8^{\circ}$ passo - Fixe a porca com adesivo epóxi em massa ao cano que liga a luneta ao tripé.

$9^{\circ}$ passo - Cole fita dupla face na borda externa do cano que está fixado a ocular de lanterna $(40 \mathrm{~mm})$.

Figura $4-10^{\circ}$ passo, $11^{\circ}$ passo e $12^{\circ}$ passo da montagem do telescópio

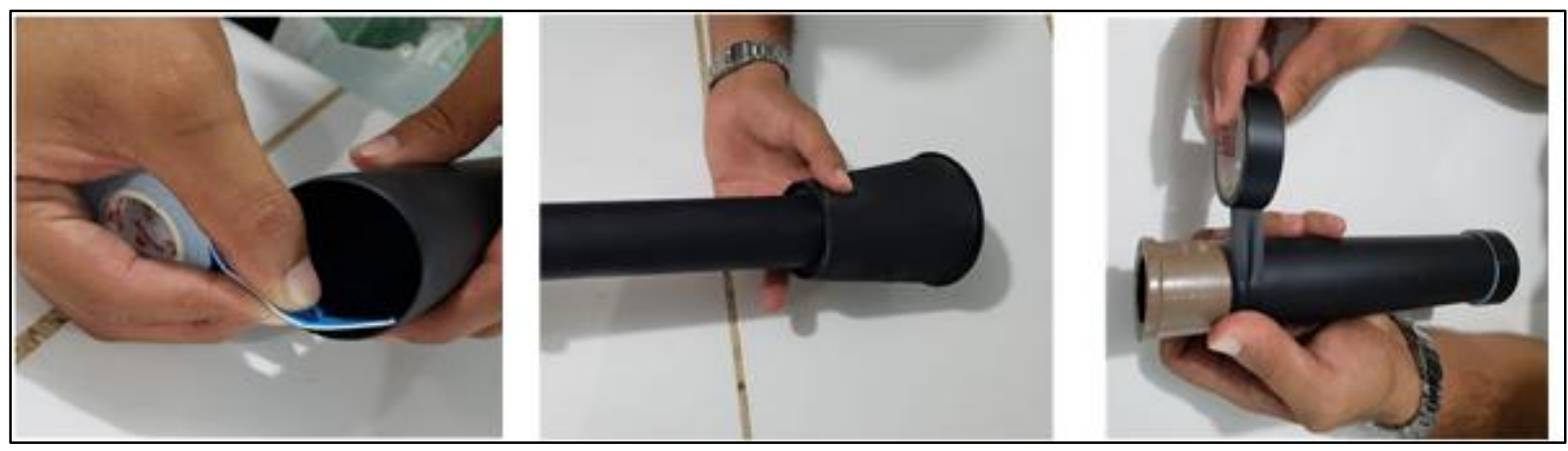

Fonte: arquivo pessoal

$10^{\circ}$ passo - Cole fita dupla face na borda interna do cano que dá suporte ao copo fixador da lente, na parte inferior $(50 \mathrm{~mm}$ de $25 \mathrm{~cm}$ ). 
$11^{\circ}$ passo - Na extremidade oposta a qual foi colada a fita dupla face, encaixe o copo plástico que está com a lente fixada.

$12^{\circ}$ passo - Fixe o cano curto que está com a lente objetiva com fita isolante ao cano de $40 \mathrm{~mm}$.

Como a observação demanda um ajuste mais fino e minucioso é interessante a base para que seja feita a observação em um ponto sem oscilação. Já que, se não houver um suporte fixo, as imagens podem ficar trêmulas dificultando a observação.

Tripé

Figura $5-13^{\circ}$ passo, $14^{\circ}$ passo e $15^{\circ}$ passo da montagem do telescópio

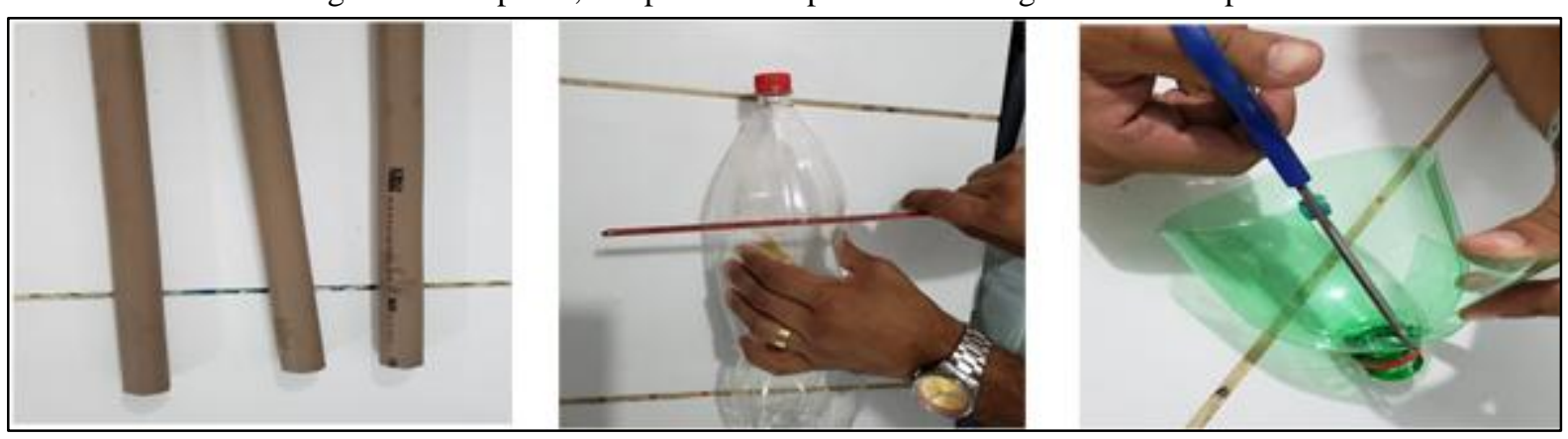

Fonte: arquivo pessoal

$13^{\circ}$ passo - Corte três pedaços de cano iguais $(1 \mathrm{~m})$.

$14^{\circ}$ passo - Corte uma garrafa pet de $2 \mathrm{~L}$ ao meio e use a parte da tampa.

$15^{\circ}$ passo - Faça três cortes no sentido vertical até chegar próximo a tampa, mas não dividir as partes.

Figura $6-16^{\circ}$ passo, $17^{\circ}$ passo e $18^{\circ}$ passo da montagem do telescópio

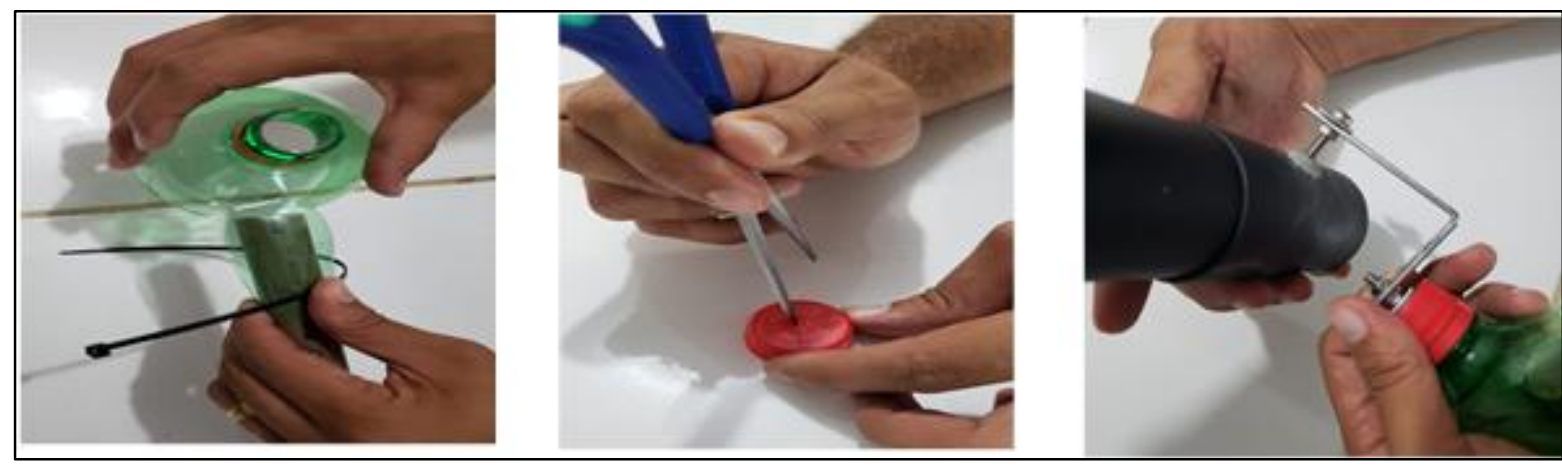

Fonte: arquivo pessoal

$16^{\circ}$ passo - Prenda os canos a garrafa pet, revestindo-os e fixando com as presilhas ou lacre. A garrafa pet prende o tripé ao telescópio.

$17^{\circ}$ passo- Efetuar um furo na tampa da garrafa proporcional ao diâmetro do parafuso. 
$18^{\circ}$ passo - Com o parafuso e a cantoneira instalada na tampa da garrafa prenda a parte superior (telescópio) à inferior(tripé).

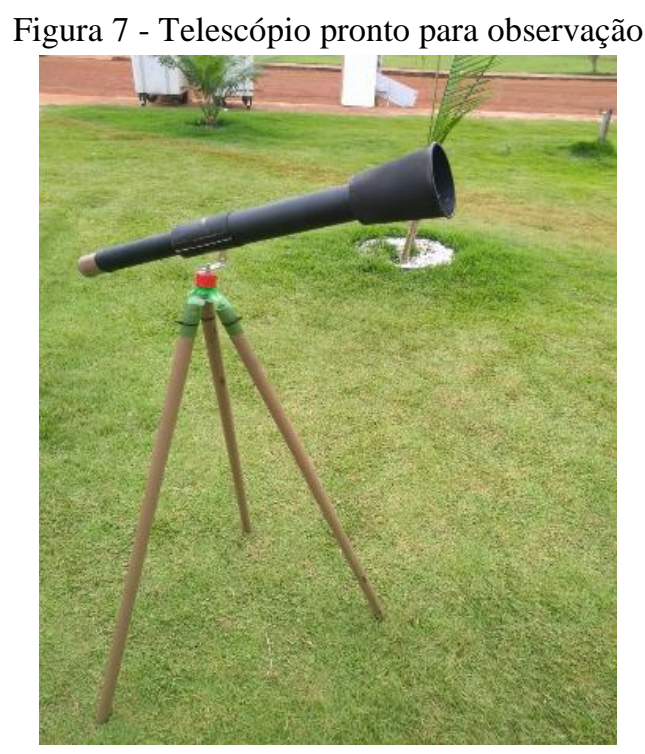

Fonte: arquivo pessoal

Os estudantes da Escola Militar Tiradentes de Confresa inseridos no projeto tiveram contato com a instrumentação física, mostrando um interesse em construir e ver os resultados. Nesse sentido obtiveram resultados satisfatório em relação a construção do telescópio, para observação de objetos celestes, participaram do desenvolvimento do projeto e associando ao cotidiano.

O projeto atingiu o objetivo esperado, pois com o telescópio refrator foi possível trabalhar com gastos moderados, como também os estudantes do ensino médio puderam trabalhar de forma teórica e prática com um equipamento didático, trabalhando a astronomia com material alternativo e acessível do ponto de vista financeiro. Além disso com pouco tempo gasto na construção do objeto. Na aula prática foi perceptível a facilidade em produzir conhecimento, mesclando curiosidade e vontade, e a baixo custo para estudantes e acadêmicos.

O experimento de observação celeste para teste de efetividade do objeto artesanal científico (lupa caseira), obteve êxito com imagens nítidas e bem aproximadas em relação a outros telescópios caseiros, com materiais de baixo custo. Não foi possível a captura de imagens, por falta de câmera apropriada para o registro. Apenas uma câmera posicionada no local de observação, não conseguiu fazer uma boa fotografia. Para fins didáticos o material alcançou o objetivo almejado com boas imagens e que possibilitou aos discentes uma observação com riqueza de detalhes dentro das limitações de um instrumento didático caseiro. 


\section{CONCLUSÃo}

A prática científica por meio de uma aprendizagem inovadora, depende de quem está buscando o conhecimento e a sua determinação. O trabalho teve ênfase em ensinar física com prática e baixo custo, isso é um passo significativo para que escolas públicas, educadores e estudantes, possam buscar o conhecimento de Física através da Astronomia (observação).

Após construir o telescópio com materiais acessíveis, foi possível perceber que o incentivo de aulas diferentes e inovadoras são uma forma de prender a atenção dos nossos estudantes e, ao mesmo tempo, é instigante o incentivo de observação a ciência e pesquisa. Existem diversas formas de se trabalhar com as aulas práticas no ensino da física, o docente precisa ser motivador para que os estudantes tenham aulas que possam ter um significado na aprendizagem com uma relação teoria/prática.

Diante da falta de equipamentos de laboratórios, para se trabalhar em escolas de Educação Básica, sobretudo nas públicas, é preciso buscar inspiração e novas ideias para se abordar uma matéria como a de Astronomia, pois mesmo complexa possui uma vasta opção de materiais alternativos com os quais podem ser utilizados, para promover a aprendizagem de forma significativa para os estudantes.

\section{REFERÊNCIAS}

CANDAU, Vera Maria (Org.). A didática em questão. 31. ed. Petrópolis-RJ: Vozes, 2011

DAMASCENO, Julio Cesar Gonçalves. O Ensino de Astronomia como facilitador nos processos de Ensino e Aprendizagem. Rio Grande: FURG/imef, 2016. Disponível em: <http://www1.fisica.org.br/mnpef/sites/default/files/produto_julio.pdf>>

FILHO, Kepler de Souza Oliveira. Teoria das Aberrações Óticas em Astro. Virtuous Tecnologia da Informação, 2018. Disponível em:

<http://astro.if.ufrgs.br/telesc/aberracao.htm>.

FRANCISCO, Patrick. Telescópio Refletor - Site Astronomia. Virtuous Tecnologia da Informação, 2013. Disponível em: 〈http://www. siteastronomia.com/telescopio-refletor $\rangle.$

FORNER, Ricardo. Equação de Gauss - Física - Cola da Web, 2000. Virtuous Tecnologia da Informação. Disponível em: 〈https://www.coladaweb.com/fisica/optica/equacao-de-gauss $\rangle$.

LANGUI, Rodolfo; NARD, Roberto. Educação em astronomia - repensando a formação de professores. São Paulo: Escrituras, 2012.

MARQUES, Mariene dos Santos; DORES, Jorge Lúcio Rodrigues das; SILVA, Josefa Rosimere Lira-da-. A Luneta de Galileu em Pergaminho Científico, 2015. Virtuous Tecnologia da Informação. Disponível em: <https://pergaminhocientifico.wordpress.com/2015/04/27/a-luneta-de-galileu/>. 
SÓ FÍSICA. Leis de Kepler . Virtuous Tecnologia da Informação, 2008-2019. Disponível em: 〈https://www.sofisica.com.br/conteudos/Mecanica/GravitacaoUniversal/lk.php〉.

SOUZA, Anderson Alves. Um modelo de Telescópio de Baixo Custo e suas Aplicações. UFMG, Serra da Piedade- Caéte: Icex Física, 2006. Disponível em:

$<$ http://www.observatorio.ufmg.br/pas66.htm>.

Recebido em:15 de abril de 2019.

Aprovado em: 18 de junho de 2019. 